\title{
FORMAÇÃO DE PROFESSORES: UMA EXPERIÊNCIA ÉTICA E ESTÉTICA
}

TEACHER TRAINING: AN ETHICAL AND AESTHETIC EXPERIENCE

\section{Carla Clauber da Silva}

\author{
Doutora em Educação pela Universidade Estadual de Campinas \\ Pesquisadora do Núcleo de Pesquisa em Arte e Educação da Universidade da Região de Joinville \\ E-mail: carlaclauber@hotmail.com \\ Sílvia Sell Duarte Pillotto \\ Doutora em Engenharia da Produção pelo Universidade Federal de Santa Catarina \\ Professora do Departamento de Artes Visuais da Universidade da Região de Joinville \\ E-mail: pillotto0@gmail.com
}

\section{RESUMO}

O artigo Formação de professores: uma experiência ética e estética é uma investigação que se desenvolve desde 2015 em um grupo de estudos com professores de Educação Infantil da Rede Municipal de Joinville (SC), pelo Programa de Extensão Arte na Escola, polo da Casa da Cultura Fausto Rocha Jr., unidade da Fundação Cultural de Joinville. O grupo se reúne quinzenalmente para pensar sua própria formação, voltada para a reflexão da arte como possibilidade de existência ética e estética. No presente artigo nosso compromisso central é refletir sobre a formação de professores e socializar algumas estratégias metodológicas, que se tornam potentes no processo de formação, especialmente aquelas conectadas a uma ética e estética da existência. Nesta pesquisa de cunho cartográfico dialogamos com autores que refletem sobre as práticas do cuidado de si, nos cadernos de artista e com a escrita de si que nos inspiraram a exercermos uma prática poética, potencializando a autoria e a vontade de criar e se reinventar na formação. Entre eles destacamos: Corazza (2001; 2004), Deleuze (1990; 2003), Deleuze e Guattari (1992), Deleuze e Parnet (1998; 2004), Foucault (1992; 1994; 2004), Imbernón (2010), Larrosa (1994; 2001; 2002; 2004), Kastrup (2015), Kastrup e Passos (2013; 2014), Masschelein e Simons (2015), Silveira (2001), Suzuki (2014) e Valde (2015). Em nossa escrita o caderno de artista ganha importante espaço, sobretudo porque oportuniza ao professor refletir sobre sua caminhada, reinventando suas práticas pedagógicas e, acima de tudo, desvelando o sujeito autônomo e sensível, que trilha o limiar da dimensão ética e estética.

Palavras-chave: Formação. Ética e estética. Cartografia. Escrita de si. Caderno de artista. 


\title{
ABSTRACT
}

The article Teacher Training: an ethical and aesthetic experience is an investigation being conducted in a study group with preschool teachers from the Joinville Municipal Network (SC) since 2015, through the Art in School Program and which is developed in Fausto Rocha Jr. House of Culture, a unit of the Cultural Foundation of Joinville. The group meets every two weeks to reflect on their own training, focusing on the idea of art as a possibility of ethical and aesthetic existence. In this article, our central commitment is to contemplate teacher education and socialize some methodological strategies that become powerful in the training process, especially those that are connected to an ethics and aesthetics of existence. In this research, which is cartographic in nature, we spoke to authors who reflect on the self-care practices in the artist's notebooks and the writing itself that inspired us to exercise a poetic practice, enhancing the authority and the will to create and reinvent. Among which the following standout: Corazza (2001; 2004), Deleuze (1990; 2003), Deleuze and Guattari (1992), Deleuze and Parnet (1998; 2004), Foucault (1992; 1994; 2004), Imbernón (2010), Larrosa (1994; 2001; 2002; 2004), Kastrup (2015), Kastrup e Passos (2013; 2014), Masschelein and Simons (2015), Silveira (2001), Suzuki (2014) and Valde (2015). In our writing, the artist's notebook gained important space, especially since it gives the teacher the opportunity to reflect on their journey, reinventing their teaching practices and above all, revealing the autonomous and sensitive subject which tracks the threshold of ethical and aesthetic dimension.

Keywords: Formation. Ethics and aesthetics. Cartography. Writing itself. Artist documents.

\section{INTRODUÇÃO: FORMAÇÃO À DERIVA}

\begin{abstract}
Mas, qual é o grau de paixão que se necessita ter com o problema, para que aceitemos ficar, por um longo tempo, estudando e pensando sobre ele? Para que aceitemos expor nossas produções, assumindo também os riscos de suas/nossas fragilidades? (CORAZZA, 2007, p. 108-109).
\end{abstract}

O grupo de estudos composto de professoras da Educação Infantil da Rede Municipal de Joinville acontece na Casa da Cultura Fausto Rocha Júnior e é uma das ações do Polo Arte na Escola, que integra a Rede Arte na Escola desde 2015. Em 2016, ao iniciar os encontros com professores da rede pública, deparamos com a necessidade de refletir sobre formação, 
problematizando algumas questões: As formações que defendemos se traduzem nas metodologias que utilizamos? Que formações temos oferecido aos professores e quais os efeitos dessas formações para a subjetividade do professor e a sua prática pedagógica?

Inúmeros teóricos, sob diferentes pontos de vista, argumentam a favor da formação de professores, posicionando-a como um dos aspectos essenciais para a melhoria da educação pública. Nesse processo podemos destacar alguns pesquisadores que repercutiram em nosso país nas últimas décadas: Perronoud (1990), que defende a importância dos professores desenvolverem competências necessárias para exercer uma prática eficaz; Donald Schön (2000) e Alarcão (2003), que apontam para a necessidade do profissional reflexivo, eliminando as dicotomias entre o ensinar e o fazer, entre a escola e a vida, sobre pesquisa e prática; Sá-Chaves (2000) reiterando as reflexões de Schulman (1986) sobre a construção da profissionalidade, em que descreve um conjunto de conhecimentos necessários à prática; Nóvoa (2011), que se debruça sobre os desafios que envolvem a formação de professores e o exercício da sua profissão, entre outros.

Nesse sentido, podemos afirmar que as pesquisas e os pesquisadores evidenciam em suas produções a complexidade da formação de professores e também que os diferentes posicionamentos acerca do que se pensa ser um processo formativo, do que se compreende como fundamental na profissionalidade docente desencadearam ao longo das últimas décadas diversas propostas de formação inicial ou contínua em nosso país.

Para Saviani (2009, p. 148), desde o século XIX, com a necessidade da universalização, configuraram-se dois modelos de formação de professores: o modelo dos conteúdos culturalcognitivos, no qual a formação do professor se esgota na cultura geral e no domínio específico dos conteúdos da área de conhecimento correspondente à disciplina que leciona, e o modelo pedagógico-didático, que se contrapõe ao anterior, considerando que a formação do professor propriamente dita só se completa com o efetivo preparo pedagógico-didático.

Ainda segundo Saviani (2009, p. 151), um dos efeitos desses dois modelos é a dissociação da função docente e, para recuperá-la, faz-se necessário considerar "o ato docente como fenômeno concreto, isto é, tal como ele se dá efetivamente no interior das escolas". Por isso, mostra-se essencial oferecer uma escuta aos professores, aos seus dilemas, aos enfrentamentos e principalmente aos efeitos desses processos a suas subjetividades, a sua relação consigo mesmo e sua profissão, afastando-nos de qualquer modelo ideal de professor, porque isso significaria pensar a formação numa perspectiva platônica: 
[...] ao formular o conceito de Professor, nos leva a esquecer tudo aquilo que é distintivo como se, no campo da Educação, além dos vários professores e de suas ações individualizadas e desiguais, houvesse algo ou alguém que fosse O Professor-Primordial (Uno, Padrão, Verdadeiro, Normal), a partir do qual todos os professores fossem formados, embora por mãos inábeis; de modo que nenhum saísse correto e fidedigno à Idéia Pura daquele Professor-Modelo, dotado de uma qualidade essencial, ou qualitas occulta, cujo nome pode ser Professoralidade, e à qual cada um e todos os professores deverão submeter-se ou se esforçarem para dela se aproximarem, como Cópias bem ou mal assemelhadas; ou, em caso contrário, serão considerados simulacros, os quais por estarem tão distante e por serem tão dessemelhante de Professoralidade (que é a causa de O Professor e de todos os professores), serão profundamente desprezados (CORAZZA, 2007, p. 18).

Masschelein e Simons (2015, p. 132) definem o professor como aquele que ama e compreende seu oficio: "um mestre que faz a escolha consciente de remover seu ofício ou negócio da esfera produtiva". Por isso, no entendimento de tais autores o professor não é um psicólogo, sociólogo, engenheiro, mulher ou homem comum, pai ou mãe, mas uma figura pública, um artista que possui uma arte incorporada, compreendida como disciplinar em seu aspecto positivo e que corresponde a uma maneira de vida:

[...] A arte de disciplinar não é apenas a arte de manter a ordem, como gostamos de acreditar, mas é também a arte de utilizar as técnicas certas para criar a atenção e o foco na sala de aula. É a disciplina não como submissão muda e punição, mas como uma técnica de atenção. E a arte de apresentar não é apenas a arte de tornar algo conhecido; é a arte de fazer algo existir, a arte de dar autoridade a um pensamento, um número, uma letra, um gesto, um movimento ou uma ação e, nesse sentido, ela traz esse algo para a vida. É a arte de trazer algo para a proximidade, envolvendo-o e oferecendo-o (MASSCHELEIN; SIMONS, 2015, p. 132).

Pensamos que a formação poderia ser voltada ao próprio sujeito, conectada a uma ética e estética da existência, ou seja, uma formação que reitera a relação do professor consigo mesmo e com o outro, assumida nas palavras de Fischer (2009, p. 95) como "escolha da própria existência, como busca de um estilo de vida, de um cuidado consigo, que de maneira alguma poderia ser identificado com o culto narcísico de nosso tempo".

Para Foucault (2004, p. 109), a estética da existência ou artes da existência se desenvolve por meio da prática de técnicas de cuidado de si. Uma experiência que visa à constituição do sujeito como ser livre, trazendo em sua prática uma ética do eu que se confronta na relação consigo mesmo e está voltada ao modo de conduzir a própria vida, a existência, negando projeções de como o sujeito deve ser na sociedade:

As "artes da existência" devem ser entendidas como as práticas racionais e voluntárias pelas quais os homens não apenas determinam para si mesmos regras de conduta, como também buscam transformar-se e modificar seu ser singular, e fazer de sua vida uma obra que seja portadora de certos valores estéticos e que corresponda a certos critérios de estilo (FOUCAULT, 2004, p. 109). 
Larrosa (2004, p. 60-73) descreve a formação como a metáfora do viajante, "do expectador errante, do homem que atravessa o mundo sem formar parte dele, daquele que está entre nós, mas que não é um de nós [...] se desfaz o que se é, separa o jovem protagonista de seu mundo e de si mesmo, e o lança a um vir a ser, aberto e indefinido". Nele não se encarna nenhum modelo de homem, assim como o Iluminismo nos fez pensar, mas antes um combate contínuo contra o que se é. Restitui-lhe sua dimensão estética ao afirmar seu sentido como a de "enriquecer a cada um de si mesmo, desvelar o que cada um é e o que tem de melhor, elevar cada um à sua própria altura, procurar em suma que cada um chegue a ser o que é" (LARROSA, 2004, p. 67).

Por isso, em nosso grupo de estudos, juntamente com os professores da rede pública, cada um tem o compromisso de desenvolver um projeto próprio, um problema singular pelo poder de lhe atravessar afetando. Nesse processo há a responsabilidade de partilhar com o grupo suas descobertas, seus desafios, suas leituras.

Por sua vez, o grupo possui o compromisso de colaborar, de ouvir, de conversar sobre os projetos de cada um deles e de seus desdobramentos, na medida em que as reflexões produzem outras narrativas, outros problemas, abrindo-se outras possibilidades e desafios.

Trata-se de um processo que vem fortalecendo o grupo e constituindo-nos enquanto uma comunidade de prática. Imbernón (2010, p. 86) nos diz que a finalidade é "informar e comunicar experiências, colocando em comum aprendizagens baseadas na reflexão compartilhada sobre experiências práticas". Ainda para o autor, uma das características principais da comunidade prática é a forte participação do grupo, em que se experimenta de diversas maneiras o objeto de conhecimento escolhido, por isso o compromisso mútuo, a ação conjunta e a bibliografia compartilhada são essenciais.

Uma condição nesse processo é apostar na singularidade e na potência de cada um e que se afasta da prática moral. Nas palavras de Schmid (2007, p. 48):

A ética da condução da vida e da práxis da liberdade substitui a moral, que foi imposta ao indivíduo a partir de uma instância codificadora, seja ela Igreja ou Estado. Na concepção desta ética, fala-se bastante em responsabilidade e em experimentação [Versuch], mas não em culpa, que é o conceito central da moral cristã. Podemos acrescentar outros conceitos: veracidade, honestidade intelectual, autoconhecimento (no sentido dos antigos), autocrítica, auto-superação: o eu [Das Selbst $]$ está no centro desta ética, assim como a aptidão para a transformação de si próprio.

É uma aposta na estética da existência, na qual se exige, como nos afirma Foucault (1994, p. 736), que “devemos não somente nos defender, mas também nos afirmar não somente 
enquanto identidades, mas enquanto força criativa" e nos voltarmos às práticas nas quais cada sujeito efetua por si mesmo e em si mesmo operações que possibilitam sua transformação com o fim de alcançar certo estado de felicidade, pureza, sabedoria ou imortalidade.

Com essas reflexões descreveremos as práticas que têm potencializado a arte da existência e deslocado o espaço da formação para um lugar de experimentação e criação. Práticas de escrita e de leitura que ganham experiência no caderno de artista, num diálogo com outras linguagens ampliando as possibilidades de reflexão, de conexões e principalmente potencializando as relações do sujeito consigo mesmo.

\section{ESCREVER COMO GESTO LITERÁRIO}

A "linguagem é meu esforço humano. Por destino tenho que ir buscar e por destino volto com as mãos vazias. Mas volto com o indizível" (LISPECTOR, 1988, p. 113).

As práticas de escrita e de leitura no processo de formação de professores em nosso grupo de estudos vêm se tornando fundamental, pois permitem o exercício do pensamento, como nos lembra Larrosa (2001, p. 21):

\footnotetext{
As palavras determinam nosso pensamento porque não pensamos com pensamentos, mas com palavras, não pensamos a partir de uma suposta genialidade ou inteligência, mas a partir de nossas palavras. E pensar não é somente "raciocinar" ou "calcular" ou "argumentar", como nos tem sido ensinado algumas vezes, mas é sobretudo dar sentido ao que somos e ao que nos acontece. E isto, o sentido ou o sem-sentido, é algo que tem a ver com as palavras. E, portanto, também tem a ver com as palavras o modo como nos colocamos diante de nós mesmos, diante dos outros e diante do mundo em que vivemos. E o modo como agimos em relação a tudo isso.
}

Nessa perspectiva, as páginas de um caderno de artista podem ser compreendidas como hypomnémata. Para Foucault (1992, p. 137), não são compreendidas como diários íntimos, ao contrário, produzem um movimento inverso que possibilita aplicar uma série de exercícios como: ler, reler, refletir, entregar-se a si mesmo, e "isto com uma finalidade que não é nada menos que a constituição de si”.

É uma escrita que, de acordo com Foucault (1992, p. 133), se ancora em três práticas: 1) leitura, porque o auxílio dos outros é necessário, porque não é possível tirar tudo de si próprio e a leitura está conectada à escrita, que recolhe a leitura e a si próprio enquanto escreve o que se leu. Leitura que se opõe à stultitia, definida pela "agitação do espírito, a instabilidade da atenção, a mudança das opiniões e das vontades", caracterizada pelo fato "de desviar o espírito para o 
futuro, de o tornar desejoso de novidades e de o impedir de se dotar de um ponto fixo pela posse de uma verdade adquirida"; 2) uma prática regrada e voluntária, de escolhas de elementos heterogêneos em que o essencial é que cada um possa considerar o que escreve, que reflita sobre a conveniência sobre o que escreve, que seja útil em função das circunstâncias que se encontra. Trata-se de uma arte da verdade contrastiva, em que se confronta o que está escrito com a singularidade da verdade que nela se verifica e a particularidade das circunstâncias que determinam o seu uso; 3) por ser uma prática de unificação que não se limita a compor uma totalidade, mas acontece no próprio ato de escrever como consequência da hypomnemata, da sua constituição, de suas leituras. Uma unificação que pode ser comparada ao processo de digestão de alimentos que se transforma em nosso corpo ao mesmo tempo em que o constitui ou, nas palavras de Foucault (1992, p. 5), “como o próprio corpo daquele que, ao transcrever as suas leituras, se apossou delas e fez sua a respectiva verdade: a escrita transforma a coisa vista ou ouvida 'em forças e em sangue'. Ela transforma-se, no próprio escritor, num princípio de acção racional".

A escrita assume no grupo de estudos uma prática de si, em que o que se escreve não é indiferente à exposição de quem escreve, é antes uma condição. O que se escreve não é apenas a produção de um conhecimento, e sim um exercício do pensamento; não é a resposta a um problema, mas a pergunta que se pergunta quando se lê e escreve. Para Blanchot (2011, p. 15), a escrita em primeira pessoa não garante autonomia:

O escritor parece senhor de sua caneta, pode tornar-se capaz de um grande domínio sobre as palavras, sobre o que deseja fazê-las exprimir. Mas esse domínio consegue apenas colocá-lo e mantê-lo em contato com a profunda passividade em que a palavra, não sendo mais do que sua aparência e a sombra de uma palavra, nunca pode ser dominada nem mesmo apreendida, mantém-se inapreensível, o momento indeciso da fascinação.

É nesse processo que a escrita deixa de ser apenas linguagem e torna-se também a busca de um estilo conectada à subjetividade de cada um. "Seja qual for o seu refinamento o estilo tem, sempre, algo de bruto: ele é uma forma sem destinação, ele é o produto de um surto, não de uma intenção [...]" (BARTHES, 2002, p. 177).

Não há um momento específico para acontecer e nem tampouco para socializar, porque é uma escrita sem finalidade; acontece como gestos. Deleuze expressa (1990, p. 231): "é o vínculo ou o enlace das atitudes entre si, a coordenação de umas com as outras, mas isso só quando não depende de uma história prévia, de uma intriga preexistente ou de uma imagem ação”. Não possui caminho linear, antes é um caminho que se faz ao caminhar. 
A escrita no processo formativo constitui uma escolha de cada um, garante o papel ativo do sujeito que se forma e pode ser comparada com a experiência estética. Uma aposta pela vida ou, dito de outro modo, um dar-se à vida. Experiência que exige dedicação, concentração, criação: encontro com a multiplicidade. Trata-se de uma tarefa e uma responsabilidade da formação e de cada um. Não há um caminho linear, somente o incentivo que cada um crie seus próprios critérios; não há uma definição do que escrever, mas a socialização e a conversa sobre o que se escreve, uma troca de afetos pela escrita que se inscreve nos cadernos de artista das professoras e um modo de cada um conversar consigo próprio.

Nesse processo a leitura ganha força e já não são somente respostas aos problemas que se busca, e sim apreciar a linguagem enquanto se lê, problematizar os efeitos da leitura enquanto se lê, refletir sobre as compreensões que se tece enquanto se lê, conectar a leitura com a vida que se vive em sala de aula e com a própria vida. Uma leitura que se abre ao porvir:

o que se deve ler na lição não é o que o texto diz, mas aquilo que ele dá o que dizer. Por isso a leitura da lição é escrita, além daquilo que o texto diz, o que o texto abriga e o que ele dá o que dizer. Ler não é apropriar-se do dito, por isso ler é trazer o dito à proximidade do que fica por perguntar (LARROSA, 1999, p. 142).

Leitura que se faz lendo, traçando um caminho que ainda não existe, acontecendo nas pausas, onde não há o escrito, feitas de imagens e audições impossíveis. Porque a atração que se sente não está no que se conta, mas no que se guarda. Leitura que acontece na improvisação que se inventa, na intimidade com a matéria-prima.

Abre-se um tempo outro; uma atmosfera de surpresa e de conversas que não aspiram a uma resposta, uma verdade única, e sim a um direito que cada um tem de se mostrar ao mundo a seu modo e de mostrar o modo como o mundo se lhe apresenta, afetando-o.

Larrosa (2004, p. 160) escreve que "a possibilidade de que algo nos passe ou nos aconteça ou nos toque requer um gesto de interrupção" no qual o "sujeito da experiência é um ser que se expõe atravessando um espaço indeterminado e perigoso, pondo-se nele à prova e buscando nele sua oportunidade, sua ocasião". Por isso a leitura e a seleção de textos são fundamentais, principalmente quando consideramos um convite ao processo de ensinar e de aprender:

Uma lição é a leitura e o comentário público de um texto cuja função é abrir o texto a uma leitura comum. Por isso, o começo da lição é abrir o livro, num abrir que é, ao mesmo tempo, um convocar. E o que se pede aos que, no abrir-se o livro, são chamados à leitura não é senão a disposição de entrar no que foi aberto. [...] Hospitalidade do livro e disponibilidade dos leitores. Mútua entrega: condição de um duplo devir (LARROSA, 1999, p. 139). 
Leitura que reivindica uma escuta e uma liberdade. Um encontro com a alteridade, em que incita o leitor a inventar outros modos de se pensar, afinando a escuta pela sensibilidade, já que o silêncio sustenta a palavra pelo avesso, movimentando-se, ou nas palavras de Larrosa em uma postura política da leitura:

Para fora porque o professor pronuncia para si mesmo e para os demais isso que diz o texto. Para dentro porque o professor diz o texto com sua própria voz, com sua própria língua, com suas próprias palavras, e esse redobrar-se do texto faz com que as palavras que o compõem soem para ele, lhe pareçam ou lhe digam de um modo singular e próprio. Para os ouvintes, porque o professor diz o texto no interior de algo que é comum, daquilo que poderíamos chamar de seu "sentido comum", aquilo que os ouvintes sentem em comum quando prestam atenção à mesma coisa e que nada mais é senão a experiência da pluralidade e do infinito do sentido (LARROSA, 1999, p. 141).

No caderno de artista, construído pelas professoras, a linguagem da escrita não é a única que está presente, há também a fotografia e o desenho. Isso porque nos envolvemos e deixamos que a experiência estética nos tomasse completamente.

\title{
3 CADERNO DE EXPERIÊNCIAS: ANTOLOGIAS DE EXISTÊNCIAS
}

\begin{abstract}
"Práticas que desfazem a compreensão, a fala, a visão e a escuta das mesmas coisas, dos mesmos sujeitos, dos mesmos conhecimentos. Desassossegam o sossego dos antigos problemas e das velhas soluções. Estimulam outros modos de ver e ser visto, dizer e ser dito, representar e ser representado" (CORAZZA, 2001, p. 30).
\end{abstract}

Já havíamos detectado no ano anterior que a formação com esse grupo de professoras necessitava ser (re)significado, pois se apresentava muito mais como uma prática mecânica e menos reflexiva e poética. Então, decidimos adotar em nossas práticas o caderno de artista como possibilidade de expressar para si e ao grupo o próprio percurso de aprendizagem e de potencializar a relação consigo mesmo por meio de uma arte da existência, em que é possível viajar para o interior de si mesmo, ensaiar-se com o outro, novas maneiras de ser.

Suzuki (2014, p. 13) nos lembra a magia que ronda o caderno de artista em nosso tempo de escola:

Na minha memória, os meus dias de escola vêm acompanhados da sensação de estreia que antecipava o retorno às aulas. Essa ansiedade vinha acompanhada de certo consumismo, de ida às papelarias e lojas que vendiam materiais escolares, lugares que criam o desejo por estojos, lápis, caneta coloridas e o tão sonhado caderno. O caderno na minha história e na de muitas outras crianças, era motivo de emancipação, autonomia, responsabilidade. Emancipava-se aquele que deixava de usar brochuras para usar o desejado "caderno de dez matérias" ou aquele que podia escolher qual caderno 
usar, pois a professora já não escolhia por nós. Autônomo, porque podia escolher a capa, os adesivos (aqueles que vinham na primeira página do caderno e eram temáticos) e organizá-los da maneira que achássemos melhor. Isso agregava responsabilidade, pois tínhamos que cuidar do nosso caderno e saber usá-lo com cuidado, já que agora havia muitas matérias para organizar no mesmo lugar, afinal de contas, não podíamos perder "nossa vida escolar".

Pelo caderno de artista, tínhamos a possibilidade de experimentar o aprender, a poética, de adentrarmos em outra temporalidade. Experiência que de algum modo pode ser comparada à de Manoel de Barros (2010, p. 15), haja vista em sua produção haver lugar para expressar nossos despropósitos, gostar "mais do vazio do que do cheio, uma vez que eles são maiores e infinitos". Fazer um caderno de artista é como "carregar água na peneira", fazer "peraltagens" com as relações e consigo mesmo. Acontece na busca dos signos ${ }^{\mathrm{i}}$, apalpando a intimidade do mundo, sentindo o que não se é na folha em branco.

O caderno de artista abriga as sensações, afetos, memórias, fragmentos que o pensamento deixa cair sobre a folha sob a forma de escrita, rabiscos, desenhos, imagens e ganham vida própria, não se trata de algo utilitário, mas “[...] a obra de um artista. Nessa condição, ele apresenta mistérios específicos que dificultam a sua presença em obras gerais, [...] ou seja, aquelas obras com participação artesanal do artista, freqüentemente em peças únicas" (SILVEIRA, 2001, p. 127).

Uma relação que ora nos aproximava umas das outras para partilhar, para aprender, para comparar, para apreciar, para escutar, ora nos distanciava para ficarmos suficientemente a sós e vivermos com o outro de nós mesmos, para habitar um outro espaço, para arriscarmos a colocar as sensações em linhas, cores, palavras, para nos pôr em movimento em uma solidão povoada de uma multidão, como nos lembram Deleuze e Parnet (1998, p. 14), e repletas de encontros:

\footnotetext{
Quando se trabalha, a solidão é, inevitavelmente, absoluta [...]. Só que é uma solidão extremamente povoada. Não povoada de sonhos, de fantasmas nem de projetos, mas de encontros [...]. É do fundo dessa solidão que se pode dar qualquer encontro. Encontramse pessoas (e por vezes sem as conhecer nem as ter jamais visto), mas também movimentos, idéias, acontecimentos, entidades. Todas estas coisas têm nomes próprios, mas o nome próprio não designa de modo algum uma pessoa ou um sujeito. Designa um efeito, um ziguezague, alguma coisa que passa ou que se passa entre dois como sob uma diferença de potencial: «efeito Compton», «efeito Kelvin».
}

O caderno de artista no decorrer dos encontros foi ocupando um espaço delicado durante as formações. Cada uma a seu modo desenvolveu uma relação particular com ele. Valdé (1995, p. 18) diz que, “dos rabiscos e anotações rápidas ou elaboradas, ele é testemunho dos processos iniciais da criação. [...] pois no caderno o artista tenta registrar uma nova concepção que surge do limbo do inconsciente [...]". 
A produção de um caderno inspirada no processo de criação do artista e na hypomnemata abre-se para um tempo outro, no qual o que é menor cria uma atmosfera de surpresa, de conversas, afetos e principalmente uma liberdade para que cada um se mostre a seu modo e o modo como o mundo se apresenta a si, afetando cada um de uma maneira particular:

O essencial são os intercessores. A criação são os intercessores. Sem eles não há obra. Podem ser pessoas - para um filósofo, artistas ou cientistas; para um cientista, filósofos ou artistas - mas também coisas, plantas, até animais, como em Castañeda. Fictícios ou reais, animados ou inanimados, é preciso fabricar seus próprios intercessores. É uma série. Se não formamos uma série, mesmo que completamente imaginária, estamos perdidos. Eu preciso de meus intercessores para me exprimir, e eles jamais se exprimiriam sem mim: sempre se trabalha em vários, mesmo quando isso não se vê. $\mathrm{E}$ mais ainda quando é visível: Félix Guattari e eu somos intercessores um do outro (DELEUZE, 1988, p. 156).

O caderno de artista entrou no grupo por meio de uma conversa que nos provocou a cada uma a produzir o seu. Em nossas mesas: papéis, cores, imagens, fios, lápis, cola, folhas, a imensidão nos tomando e a sensação de que tínhamos de continuar, sem saber.

Eu atravesso as coisas - e no meio da travessia não vejo! - só estava era entretido na idéia dos lugares de saída e de chegada. [...] A gente quer passar um rio a nado, e passa; mas vai dar na outra banda é num ponto muito mais embaixo, bem diverso do que em que primeiro se pensou (ROSA, 1994, p. 43).

A liberdade possibilita que algo aconteça, deslize, intensificando a curiosidade por indagar, experimentando perplexidades e que faz da formação uma fabulação. Planejávamos com o nosso próprio corpo, como se quiséssemos capturar neblina, como nos lembra Brígida Baltar (2016), transformando o comum em algo raro, singular. São possibilidades de existir encontradas nas linhas de fuga e que instituem um novo estilo: "São estilos de vida, sempre implicados, que nos constituem de um jeito ou de outro [...]. Há nisso uma ética, há também um estilo de vida, de nenhum modo algo pessoal, mas a invenção de uma existência” (DELEUZE; GUATTARI, 1992, p. 192), que não se prende à representação, não busca conceituar, distinguir, comparar, ordenar; contudo, por enquanto, segue perguntando.

\section{4 (IN)CONCLUSÕES}

"Nunca as coisas se passam aí onde se pensa, nem pelos caminhos que se espera" (DELEUZE; PARNET, 2004).

Nossa pesquisa, ainda (in)concluída, possibilita-nos identificar algumas pistas sobre as metodologias que potencializam a experiência estética na formação, porque não nos impede de 
"descrever, discutir e, sobretudo, coletivizar a experiência do cartógrafo", mas insistimos que nosso objetivo não é "definir um conjunto de regras abstratas para serem aplicadas. Não se busca estabelecer um caminho linear para atingir um fim" (KASTRUP, 2015, p. 54).

O movimento do grupo de estudos permitiu-nos pensar que no campo de formação de professores as artes de existências configuram relações mais livres e inventivas voltadas à invenção de si e do mundo.

A formação compreendida como espaço de experimentação ocupa-se da potencialização do pensamento, não está conectada com a fragmentação e hierarquização do saber fragmentado, imposto pelo ensino. Inverte o modelo da racionalidade técnica, que tem suas raízes a busca pela verdade para um modelo provisório, inacabado, em vias de se fazer, a cada vez o conhecimento produzido. Uma formação que suspende o saber e o poder, pois não se sabe e não se pode tudo, mas por outro lado é portadora de uma verdade a qual se deve escutar:

Pensá-la como um tipo particular de relação, como uma relação de produção de sentido [...] a formação implica, necessariamente, nossa capacidade de escutar (ou de ler) isso que as coisas (textos, filmes, notícias, pessoas, objetos, animais, cotidiano, etc.) têm a nos dizer. Uma pessoa que não é capaz de se pôr à escuta cancelou seu potencial de formação e de transformação (LARROSA, 2002, p. 133).

Uma escuta que é potencializada pela conversa, pela leitura e pela escrita, possibilitando-nos viver o aprender e, ao mesmo tempo, nos afastar de uma formação fundada em uma racionalidade técnico-científica, que transforma os efeitos, as sensações, a subjetividade a partir da moral, do que é certo, produzindo contratos, estatutos, doutrinas que normatizam a constituição do professor.

Um aprender que se dá em presença consigo e com o outro, nas relações entre o grupo, em deixar ser afetado e vai ganhando força junto com a constituição do grupo, no encontro sensível com os signos, como nos lembra Deleuze (2003, p. 4), pois "são um aprendizado temporal, não de um saber abstrato. Aprender é, de início, considerar uma matéria, um objeto, um ser, como se emitissem signos a serem decifrados, interpretados".

Outra pista foi a potência do caderno de artista, tendo como referência a escrita de si.

Fazer autorretrato escapando da capacidade de compreensão, da necessidade de se representar enquanto ser idealizado, de se confessar como prática cristã, mas de fabular-se, como nos mostra Borges (1998, p. 168):

Um homem se propõe a tarefa de desenhar o mundo. Ao longo dos anos, povoa um espaço com imagens de províncias, de reinos, de montanhas, de baías, de naus, de ilhas, de peixes, de moradas, de instrumentos, de astros, de cavalos e de pessoas. Pouco antes de morrer, descobre que este paciente labirinto de linhas traça a imagem de seu rosto. 
Nessa perspectiva, podemos afirmar que o caderno de artista possibilitou fazer da formação uma prática poética e potencializou a autoria e a vontade de criar e de se inventar, uma vez que não é compreendido como registro do vivido, nem como cópia, e sim como processo de produção de subjetividade e signos.

Para nós, formadores, exige conceber a formação com base na experiência, compreendendo-a como um espaço de multiplicidades: ora são lugares de encontros, de resistências e de potência, às vezes tolhidos, às vezes fragmentados; por vezes fabricados, ora inventados. Nosso compromisso é deixar que a arte habite a formação:

Arte é uma prática de problematização [...]. É exatamente nessa interferência na cartografia vigente que a prática estética faz obra, sendo o bem sucedido da forma indissociável de seu efeito de problematização do mundo. O mundo liberta-se de um olhar que o reduz às suas formas constituídas e sua representação, para oferecer-se como matéria trabalhada pela vida enquanto potência de variação e, portanto, matéria em processo de arranjo de novas composições e engendramento de novas formas. A arte participa da decifração dos signos das mutações sensíveis, inventando formas através das quais tais signos ganham visibilidade e integram-se ao mapa vigente. A arte é portanto uma prática de experimentação que participa da transformação do mundo (ROLNIK, 2002, p. 271).

Finalizando o artigo, sem, contudo, termos respostas definitivas para nossas inquietações, voltamos às duas questões iniciais de nossa pesquisa: As formações que defendemos se traduzem nas metodologias que utilizamos? Que formações temos oferecido aos professores e quais os efeitos dessas formações para a subjetividade do professor e a sua prática pedagógica?

$\mathrm{Na}$ maioria das vezes, observamos que as formações não traduzem as metodologias adotadas. Essa foi nossa primeira inquietação e, por isso, decidimos mudar a rota de nossa caminhada com o grupo de estudos. Não estamos preocupadas com o sucesso ou não dos resultados, queremos refletir sobre nossa própria formação, agregando a existência ética e estética, de modo a nos possibilitar um movimento de busca e descobertas sobre nossas práticas e sobre o que essas práticas podem implicar no encontro com o outro - alunos, outros professores, gestores e comunidade.

A outra inquietação - que formações temos oferecido aos professores e quais os efeitos dessas formações para a subjetividade do professor e a sua prática pedagógica - impulsionounos a criar alternativas metodológicas, colocando-nos frente a frente com o caderno de artista. Pensamos: no grupo de estudos por que não nos apropriarmos de uma prática e um produto utilizado basicamente por artistas? 
Para nossa surpresa, a escolha tomou também para si dois elementos que foram fundamentais: a ética e a estética em nossas práticas e na formação. A ética como uma atitude, que define estar só e estar com o outro. E a estética como reflexão de quem somos para nós e para o outro, que existência é essa repleta de incertezas, muito mais do que certezas, que mescla dor e alegria, medo e vontade, procura e desejo, que desvela, sem muito revelar!

Esse tem sido o nosso processo no grupo de estudos. Um processo que não impõe verdades absolutas, mas que se mantém aberto ao encontro, à busca infinita de quem somos e quais caminhos decidimos trilhar nesta tão turbulenta e encantadora existência de ser/estar professor(a)!

\section{NOTA}

1 Segundo Deleuze (2003, p. 4), o aprender remete aos signos: "Os signos são objeto de um aprendizado temporal, não de um saber abstrato. Aprender é, de início, considerar uma matéria, um objeto, um ser, como se emitissem signos a ser decifrados, interpretados. Não existe aprendiz que não seja 'egiptólogo' de alguma coisa. Alguém só se torna marceneiro tornando-se sensível aos signos da madeira, e médico, tornando-se sensível aos signos da doença. A vocação é sempre uma predestinação com relação a signos. Tudo que nos ensina alguma coisa emite signos, todo ato de aprender é uma interpretação de signos ou de hieróglifos".

\section{REFERÊNCIAS}

ALARCÃO, I. Professores reflexivos em uma escola reflexiva. 8. ed. São Paulo: Cortez, 2003.

BALTAR, B. Brígida Baltar. Enciclopédia Itaú Cultural. Disponível em: $<$ http://enciclopedia.itaucultural.org.br/pessoa17557/brigida-baltar>. Acesso em: 2016.

BARROS, M. de. Poesia completa. São Paulo: Leya, 2010.

BARTHES, R. Oeuvres complètes: livres, textes, entretiens. 2. ed. Paris: Seuil, 2002.

BLANCHOT, M. O espaço literário. Tradução de Álvaro Cabral. Rio de Janeiro: Rocco, 2011.

BORGES, J. L. Obras completas. Tradução de Carlos Nejar. Rio de Janeiro: Globo, 1998. v. I.

CORAZZA, S. Na diversidade cultural, uma docência artística. Pátio - Revista Pedagógica, Porto Alegre, ano V, n. 17, 2001.

. O que Deleuze quer da educação. Revista Educação: Deleuze pensa a educação, São Paulo, v. especial, 2007.

. Pesquisar o acontecimento: estudo em XII exemplos. In: TADEU, T.; CORAZZA, S.; ZORDAN, P. Linhas de escrita. Belo Horizonte: Autêntica, 2004.

DELEUZE, G. Cinema 2 - a imagem-tempo. São Paulo: Brasiliense, 1990. 

Graal, 1988.

Diferença e repetição. Tradução de Luiz Orlandi e Roberto Machado. Rio de Janeiro:

Proust e os signos. 2. ed. Rio de Janeiro: Forense Universitária, 2003.

; GUATTARI, F. O que é a filosofia? Rio de Janeiro: 34, 1992.

; PARNET, C. Diálogos. Tradução de Eloisa Araújo Ribeiro. São Paulo: Escuta, 1998.

; ___ . Diálogos. Tradução de José Gabriel Cunha. Lisboa: Relógio d’Água, 2004.

FISCHER, R. M. B. Docência, cinema e televisão: questões sobre formação ética e estética. Revista Brasileira de Educação, Rio de Janeiro, n. 40, jan./abr. 2009.

FOUCAULT, M. A escrita de si. In: O que é um autor? Lisboa: Passagens, 1992.

. A hermenêutica do sujeito. 6. ed. São Paulo: Martins Fontes, 2004.

Dits et Écrits. v. III. Paris: Gallimard, 1994.

IMBERNÓN, F. Formação continuada de professores. Porto Alegre: Artmed, 2010.

KASTRUP, V. Aprendizagem, arte e invenção. Psicologia em Estudo: Educação \& Sociedade, v. 6 , n. 1, p. 17-27, jan. /jun. 2000 .

- O funcionamento da atenção no trabalho cartográfico. In: ; PASSOS, E.; ESCÓSSIA, L. (Orgs.). Pistas do método da cartografia: pesquisa-intervenção e produção de subjetividade. Porto Alegre: Sulina, 2015.

; PASSOS, E. Cartografar é traçar um plano comum. Fractal - Revista de Psicologia, v. 25, n. 2, jan./ago. 2013. Disponível em: <http://www.scielo.br/scielo.php?script=sci_arttext\&pid=S1984-02922013000200004>.

Cartografar é traçar um plano comum. In: ; TEDESCO, S. (Orgs.). Pistas do método da cartografia: a experiência da pesquisa e o plano comum. Porto Alegre: Sulina, 2014.

LARROSA, J. Linguagem e educação depois de Babel. Tradução de Cynthia Farina. Belo Horizonte: Autêntica, 2004.

Literatura, experiência e formação. In: COSTA, M. V. Caminhos investigativos novos olhares na pesquisa em educação. Rio de Janeiro: DP\&A, 2002.

Notas sobre a experiência e o saber de experiência. Palestra. In: COLE - CONGRESSO DE LEITURA DO BRASIL, 13., 2001, Campinas.

Pedagogia profana: danças, piruetas e mascaradas. Tradução de Alfredo Veiga Neto. Belo Horizonte: Autêntica, 1999.

Tecnologias do eu e educação. In: SILVA, T. T. da. (Org.). O sujeito da educação estudos foucaultianos. Petrópolis: Vozes, 1994. 
LISPECTOR, C. Água viva. Rio de Janeiro: Rocco, 1998.

MASSCHELEIN, J.; SIMONS, M. Em defesa da escola - uma questão pública. Belo Horizonte: Autêntica, 2015.

NÓVOA, A. O passado e o presente dos professores. Porto: Porto, 2011.

PERRENOUD, P. Dez novas competências para ensinar. Porto Alegre: Artmed, 1990.

ROLNIK, S. Subjetividade em obra: Lygia Clark, artista contemporânea. In: LINS, D.; GADELHA, S. Nietszche e Deleuze: o que pode o corpo. Rio de Janeiro: Relume Dumará, 2002. p. 269-280.

ROSA, J. G. Grande sertão: veredas. Rio de Janeiro: Nova Aguilar, 1994.

SÁ-CHAVES, I. Formação, conhecimento e supervisão: contributos na área de formação de professores e outros profissionais. Aveiro: Universidade, 2000.

SANTI, P. L. R. Montaigne e a reflexão moral do século XVI. Revista Olhar, ano 5, n. 7, jan./jun., 2003.

SANTOS, T. A. de O. A coisa e o olho: uma abordagem da direção de atores no teatro de Samuel Beckett. Dissertação (Mestrado)-Universidade Estadual Paulista, São Paulo, 2013.

SAVIANI, D. Formação de professores: aspectos históricos e teóricos do problema no contexto brasileiro. Revista Brasileira de Educação, v. 14, n. 40, jan./abr. 2009.

SCHMID, W. Dar forma a nós mesmos. Sobre a filosofia da arte de viver em Nietzsche. Revista Verve, n. 12, p. 44-64, 2007.

SILVEIRA, P. A. A página violada: da ternura à injúria na construção do livro de artista. Porto Alegre: Editora da UFRGS, 2001.

SCHÖN, D. A. Educando o profissional reflexivo: um novo design para o ensino e a aprendizagem. Porto Alegre: Artmed, 2000.

SHULMAN, L. S. Those who understand: knowledge growth in teaching. Educational Researcher, v. 15, n. 2, p. 4-14, 1986.

SUZUKI, C. L. Caderno de artista: páginas que revelam olhares da arte e da educação. Dissertação (Mestrado)-Programa de Pós-Graduação em Artes Visuais, Escola de Comunicação e Artes, Universidade de São Paulo, São Paulo, 2014.

VALDÉ, J. L. Carnet de Paris 1900. Madri: Casariego, 1995. Disponível em: $<$ http://diariografico.com/htm/outrosautores/Picasso/Picasso03.htm>. Acesso em: 23 jul. 2015.

VISCONTI, J. C. Novas derivas. Tese (Doutorado)-Universidade de São Paulo, São Paulo, 2012. 